\title{
Effect of Potential and Microstructure on the Tribocorrosion Behaviour of Beta and Near Beta Ti Alloys II
}

\author{
Mozart Queiroz Neto $^{1}$ [D . William Mark Rainforth ${ }^{1}$
}

Received: 2 March 2021 / Revised: 17 July 2021 / Accepted: 29 August 2021 / Published online: 6 September 2021

(c) The Author(s) 2021

\begin{abstract}
Titanium alloys, especially Ti6Al4V, are commonly applied in orthopaedic implants as a result of their relatively low density, good corrosion properties, satisfactory biocompatibility and bone ingrowth promoting properties. However, Ti implants are susceptible to mechanical failure. Although corrosion and wear related problems have been recognized as a major issue impeding their long-term application, there is still a lack of knowledge about the basic mechanisms. Previously, the tribocorrosion properties of 4 distinct titanium alloys (Ti13Nb13Zr, Ti12Mo6Zr2Fe, Ti29Nb13Ta4.6Zr aged at $300{ }^{\circ} \mathrm{C}$ and at $400{ }^{\circ} \mathrm{C}$ ) was analysed in the published Part I of this study in regard to wear rates, electrochemical behaviour, and the tribocorrosion synergism estimations. This work, Part II, contributes to the previous study and investigates the tested surfaces of these 4 Titanium alloys from the same tribosystem aiming to characterize the wear track surfaces and identify the main wear mechanism, to characterize the tribofilm and to investigate the subsurface alterations occurring under varying contact pressures and electrochemical potentials. The results indicated a dominant abrasion wear mechanism regardless of microstructure, electrochemical potential and normal load (contact pressure). Additionally, grain refinement observed on the subsurface varied with alloy and electrochemical potential, with the variation being mostly independent of alloy microstructure. Finally, a graphitic tribofilm was detected in most conditions, which while inconsequential in regard to wear, may explain the previously observed reduction of friction.
\end{abstract}

\section{Graphic Abstract}

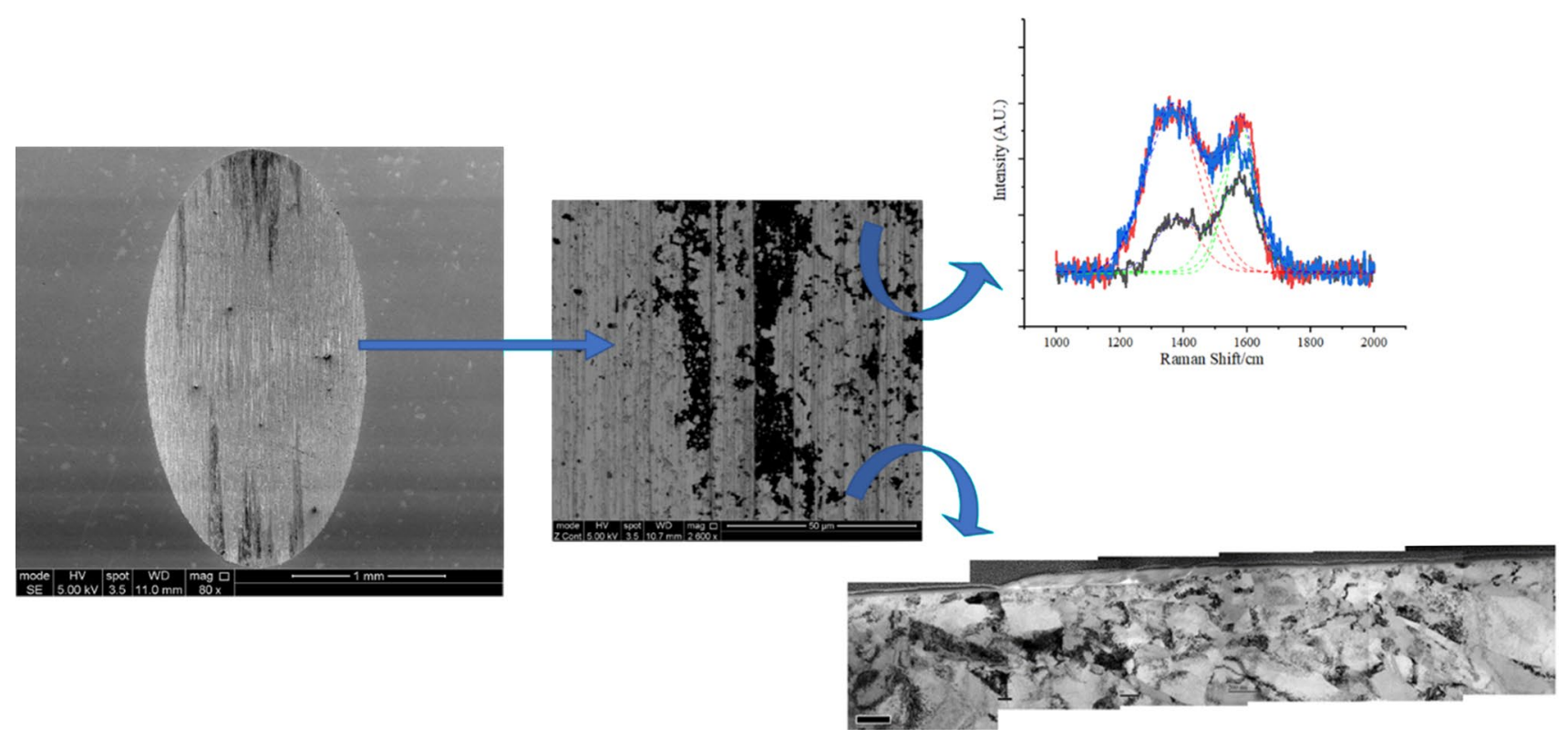

Extended author information available on the last page of the article 
Keywords Tribocorrosion $\cdot$ Beta titanium alloys $\cdot$ Tribofilm $\cdot$ Abrasion wear

\section{Introduction}

Titanium alloys, especially Ti6Al4V, are commonly applied in orthopaedic implants such as tibial trays, femoral stems, modular neck components and acetabular cups, due to their relatively low density, good corrosion properties, and satisfactory biocompatibility [1]. These alloys are also recognized for promoting bone ingrowth. However, Titanium alloys have been shown to have a relatively inferior wear resistance in comparison to $\mathrm{CoCr}$ and stainless steel [2-4]. Although titanium implants have an acceptable life expectancy, premature failure can occur. Gilbert et al. [5] reported that a new corrosion mechanism observed on a retrieved Ti6Al4V/Ti6A-4 V neck-stem taper interface led Ti6Al4V implants to failure only 6 years in situ, where corrosion selectively attacked the $\beta$ phase and eventually consumed the $\alpha$ phase. Rodrigues et al. [6] also observed severe corrosion and precipitation of brittle hydrides during combined crevice and fretting corrosion in the modular junctions of retrieved total hip replacements (THR) with a Ti6Al4V/Ti6Al4V interface. Additionally, Hall et al. [7] reported the preferential dissolution and corrosion of $\beta$ phase on dual-modular neck of the femoral stem made of Ti6Al4V. Although the low elastic moduli of Ti6Al4V $(\sim 112 \mathrm{GPa})$ results in lower stress-shielding at the implant/bone interface compared to CoCrMo alloy and stainless steels, an even lower modulus would be preferable. However, the introduction of $\beta$ Ti alloy ( $E=48-91 \mathrm{GPa}$ ) femoral stems resulted in multiple reports of catastrophic trunnion failure [8-10].

Although corrosion and wear-related problems have been recognized as a major issue impeding their long-term application, there is still a lack of knowledge about the basic underlying mechanisms [11]. Moreover, it is well-known that microstructure and alloy composition drive the mechanical and corrosion behaviour of any given alloy [12-16]. However, the microstructural features of implants may vary broadly due to chemical composition and different manufacturing processes applied. Nonetheless, the effect of microstructure on wear and corrosion behaviour is still topic of investigation [17-20]. Therefore, with regard to orthopaedic implants, it is important to comprehend the effect of the microstructural features on the tribocorrosion properties and its underlying mechanisms.

Previously, the published Part I of this study explored 4 distinct titanium alloys (Ti13Nb13Zr, Ti12Mo6Zr2Fe, Ti29Nb13Ta4.6Zr aged at $300{ }^{\circ} \mathrm{C}$ and at $400{ }^{\circ} \mathrm{C}$ ), where outputs including wear rates, electrochemical behaviour and the tribocorrosion synergism estimations were assessed [21]. The results showed that the microstructure influences the tribocorrosion properties of titanium alloys, where lower wear track volume, material loss and friction were observed on the alloys with $\alpha$ phase, especially at anodic condition. Additionally, low wear rates were attributed to the $3^{\text {rd }}$ bodies and their lubricating properties. The principal reason of material loss was mechanical wear and this was independent of the electrochemical condition, contact pressure and type of microstructure.

This work, Part II, expands on the previous study and investigates the tested surfaces of these 4 Titanium alloys (Ti13Nb13Zr, Ti12Mo6Zr2Fe, Ti29Nb13Ta4.6Zr aged at $300{ }^{\circ} \mathrm{C}$ and at $400{ }^{\circ} \mathrm{C}$ ) from the same tribosystem previously reported to a) identify the dominant wear mechanism, b) characterize the present tribofilm and c) characterize the worn subsurface area after tribocorrosion testing under various contact pressures (high pressure sliding condition) and electrochemical potentials in a simulated joint fluid at $37^{\circ} \mathrm{C}$.

\section{Methods}

All alloy samples were manufactured by arc melting (Arcast, USA) and then subjected to section reduction by rolling mill and heat treatments to obtain different microstructures. The 4 titanium alloys were classified according to their microstructure: $\alpha \beta$ alloy (Ti13Nb13Zr), N $\beta$ alloy (Ti12Mo6Zr2Fe), $\beta$ alloy (Ti29Nb13Ta4.6Zr aged at $400{ }^{\circ} \mathrm{C}$ ) and $\beta \omega$ alloy (Ti29Nb13Ta4.6Zr aged at $300{ }^{\circ} \mathrm{C}$ ). These abbreviations
Table 1 Chemical composition of the 4 titanium alloys of this study

\begin{tabular}{|c|c|c|c|c|c|c|c|c|c|}
\hline \multirow{2}{*}{$\begin{array}{l}\text { Alloy micro- } \\
\text { structure }\end{array}$} & \multicolumn{6}{|c|}{ Composition (\% weight) } & \multirow{2}{*}{$\begin{array}{l}\text { Elastic modulus } \\
\mathrm{GPa}\end{array}$} & \multirow{2}{*}{$\begin{array}{l}\text { Hardness } \\
\text { GPa }\end{array}$} & \multirow{2}{*}{$\begin{array}{l}\text { Surface } \\
\text { roughnes } \\
(\mathrm{Ra}) \\
\mathrm{nm}\end{array}$} \\
\hline & $\mathrm{Nb}$ & $\mathrm{Ta}$ & $\mathrm{Zr}$ & Mo & $\mathrm{Fe}$ & $\mathrm{Ti}$ & & & \\
\hline$\alpha \beta$ & 13 & - & 11 & - & - & bal & 96.6 & 3.5 & 20 \\
\hline $\mathrm{N} \beta$ & - & - & 4 & 11 & 2 & bal & 83.1 & 2.9 & 20 \\
\hline$\beta$ & 30 & 13 & 3 & - & - & bal & 70.3 & 2.9 & 20 \\
\hline$\beta \omega$ & 30 & 13 & 3 & - & - & bal & 89.3 & 2.8 & 20 \\
\hline
\end{tabular}


were adopted from the previously published Part I of this study [21] and Table 1 shows the alloys' composition.

\subsection{Tribocorrosion Procedure}

A tribosystem (UMT Multi Specimen Test System, Bruker UK) was used to conduct the reciprocating sliding wear tests, Fig. 1. An alumina ball (Oakwase Ltd., UK) was chosen as an inert counterface. This tribosystem does not represent a specific implant application, but rather serves as a baseline system for a comparative assessment of the tribocorrosion properties of the four chosen titanium alloys and for further comparison with other previously published work [22-24]. The test were performed at $37^{\circ} \mathrm{C}$ in a simulated joint fluid consisting of new-born calf serum with a protein concentration of $15.5 \mathrm{~g} / \mathrm{L}$ (First Link (UK) Ltd.). The applied normal loads (contact pressure) were $0.5 \mathrm{~N}$ (521 MPa), $1 \mathrm{~N}(657 \mathrm{MPa}$ ) and $2 \mathrm{~N}$ (827 MPa) to simulate a high-pressure sliding test. Three electrochemical conditions were chosen for the tribocorrosion tests: cathodic potential $(-1 \mathrm{~V}$ vs $\mathrm{OCP})$, at $\mathrm{OCP}$, and at anodic potential $(0.3 \mathrm{~V}$ vs OCP). OCP was used as reference to provide a repeatable cathodic/anodic shift. All test conditions were performed in duplicate.

\subsection{Wear Track Characterization}

The tested surfaces were ultrasonically cleansed with isopropanol for $10 \mathrm{~min}$ prior to characterization by Scanning Electron Microscopy (SEM, FEI InspectF, Netherlands) at an accelerating voltage of $5 \mathrm{kV}$. Additionally, Raman spectroscopy (inVia Renishaw, UK) at a power of $20 \mathrm{~mW}$ was used to analyse the tested surfaces to identify the chemical nature of resulting tribofilms or deposits in different positions of the wear track and repeated 5 times. Finally, baseline correction, data smoothing, curve normalisation and Gaussian peak fitting were carried out for curve fitting.
Nanoindentation (Hysitron, TI Premier, USA) was conducted to assess the reduced elastic modulus and nanohardness of the wear tracks as function of the contact depth. A peak load was applied in the center of each wear track to define the average values.

The tested surfaces were analysed by a Focused Ion Beam (FIB FEI Quanta 200 3D, Netherlands) and a Transmission Electron Microscope (TEM JEOL JEM-F200) at $120 \mathrm{kV}$ accelerating voltage with a housed Energy Dispersive X-ray spectrometer (EDS, Oxford Instruments). A complete description of the sample preparation, tribocorrosion tests and surface characterization are detailed in our previous work $[21,25]$.

\section{Results}

Damage features found on wear tracks were observed to be similar and independent of alloy composition, electrochemical condition, and contact pressure. The BSE (chemical composition contrast) and SE (topography contrast) images revealed the characteristics of the wear track surface of the $\beta \omega$ alloy, Fig. 2, where plastic deformation with abrasive grooves aligned in the direction of sliding were identified. Wear debris were not observed and the appearance of the straight grooves was indicative of micro-ploughing. Dark deposits identified on all wear tracks may indicate corrosion product deposits or the presence of a tribofilm. However, deposit films were not continuous across the entire worn surface, Fig. 2.

Deposits were further analysed where measurements from 5 different areas were taken (Fig. 3). Across all samples, most probed areas exhibited a characteristic Raman spectrum with a double peak at wavenumbers $1383 \mathrm{~cm}^{-1}$ and $1567 \mathrm{~cm}^{-1}$. Further curve fitting revealed characteristic peaks of $\mathrm{D}$ and $\mathrm{G}$ bands. Areas without this characteristic
Fig. 1 A schematic of the tribocorrosion system adapted from [55]. ( $W E$ working electrode, $R E$ reference electrode, $C E$ counter electrode, TS thermometer, $F$ normal load, $B S$ bovine serum)

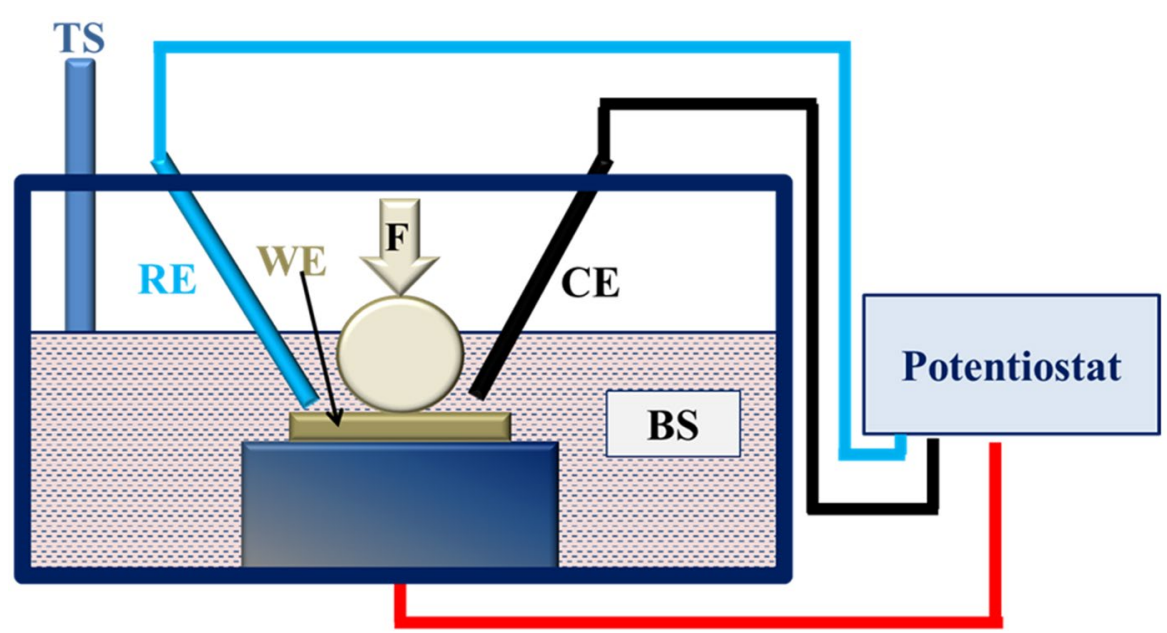


Fig. 2 Perspective of the wear track at (a) low magnification, (b) Backscattered Electron (BSE) and (c) Secondary Electrons (SE) images of the inside of the wear track ( $\beta \omega$ alloy) tested at cathodic condition at $2 \mathrm{~N}$ load. Dark deposits between grooves indicate a non-continuous film deposition
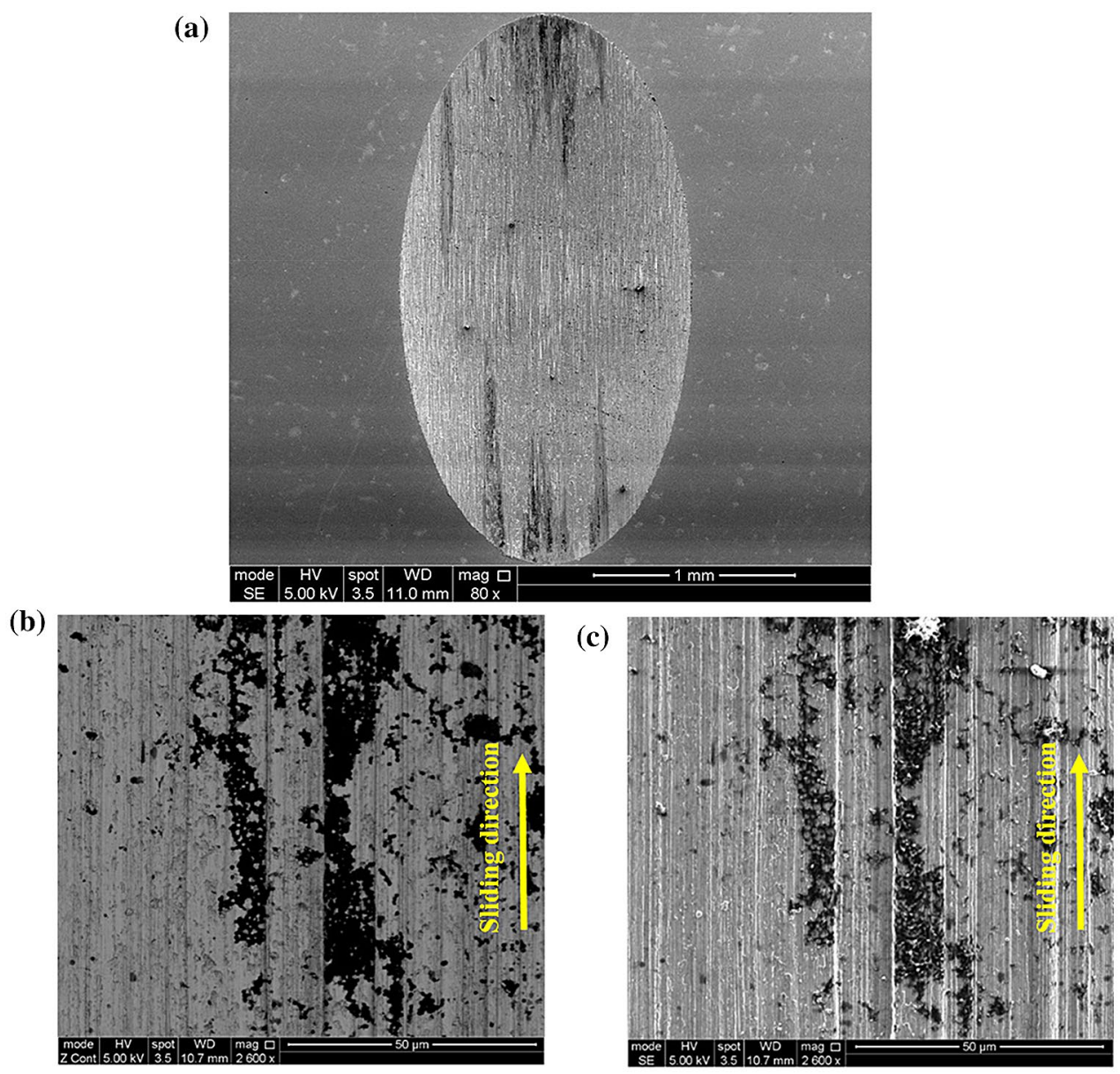

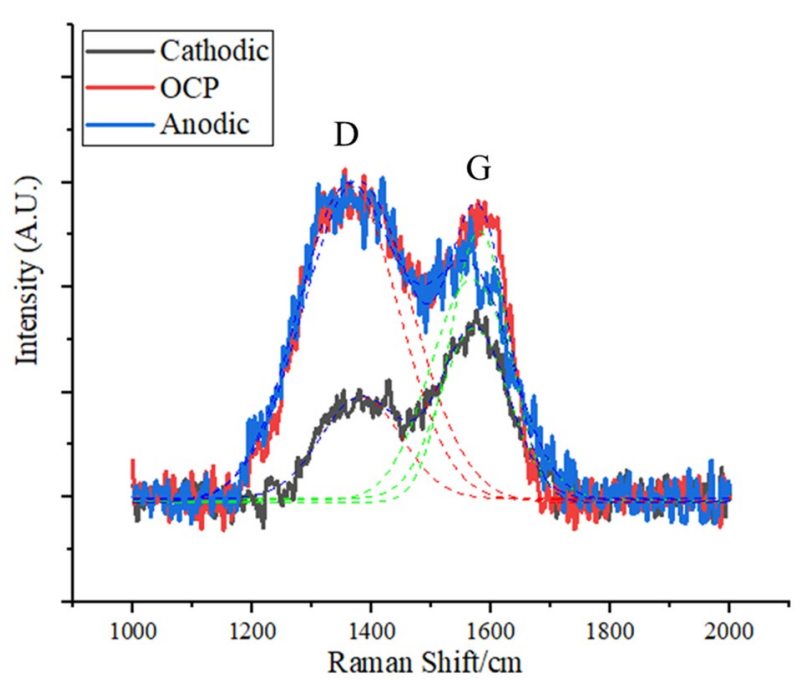

Fig. 3 Raman spectra of the inside of the wear track at $0.5 \mathrm{~N}(\beta$ alloy), which is representative of all alloy samples in this study double peak showed no identifiable peaks, indicating the nonexistence of a film.

The mechanical properties_elastic moduli (a) and nanohardness (b) - of the tested surfaces were compared between the worn surfaces and the initial unworn surfaces, Fig. 4. The highest reduced elastic moduli of the initial surface (unworn) was observed on the $\alpha \beta$ alloy (96.6 GPa), while the lowest value was found on $\beta$ alloy $(70.3 \mathrm{GPa})$, respectively. The wear track of $\alpha \beta$ alloy, especially tested at cathodic potential, had the highest reduced elastic moduli (unworn surface: 97 GPa; cathodic potential: $101 \mathrm{GPa}$; OCP: $99 \mathrm{GPa}$ and anodic: $98 \mathrm{GPa}$ ). A similar trend was identified on the worn surfaces of $\beta \omega$ alloy, where the surfaces tested at cathodic condition also had high observed reduced elastic moduli (104 GPa). On the other hand, the surfaces $N \beta$ and $\beta$ alloys tested at cathodic condition showed lower reduced elastic modulus of 88 and $93 \mathrm{GPa}$, respectively.

The nanohardness of the wear tracks were also generally increased compared to that of the initial surface (unworn). More specifically, the initial surface (unworn) of $\alpha \beta$ alloy had an average nanohardness of $3.5 \mathrm{GPa}$, whereas the average value of the surface tested at cathodic potential was 4.3 $\mathrm{GPa}$. However, it is important to note that the results were 

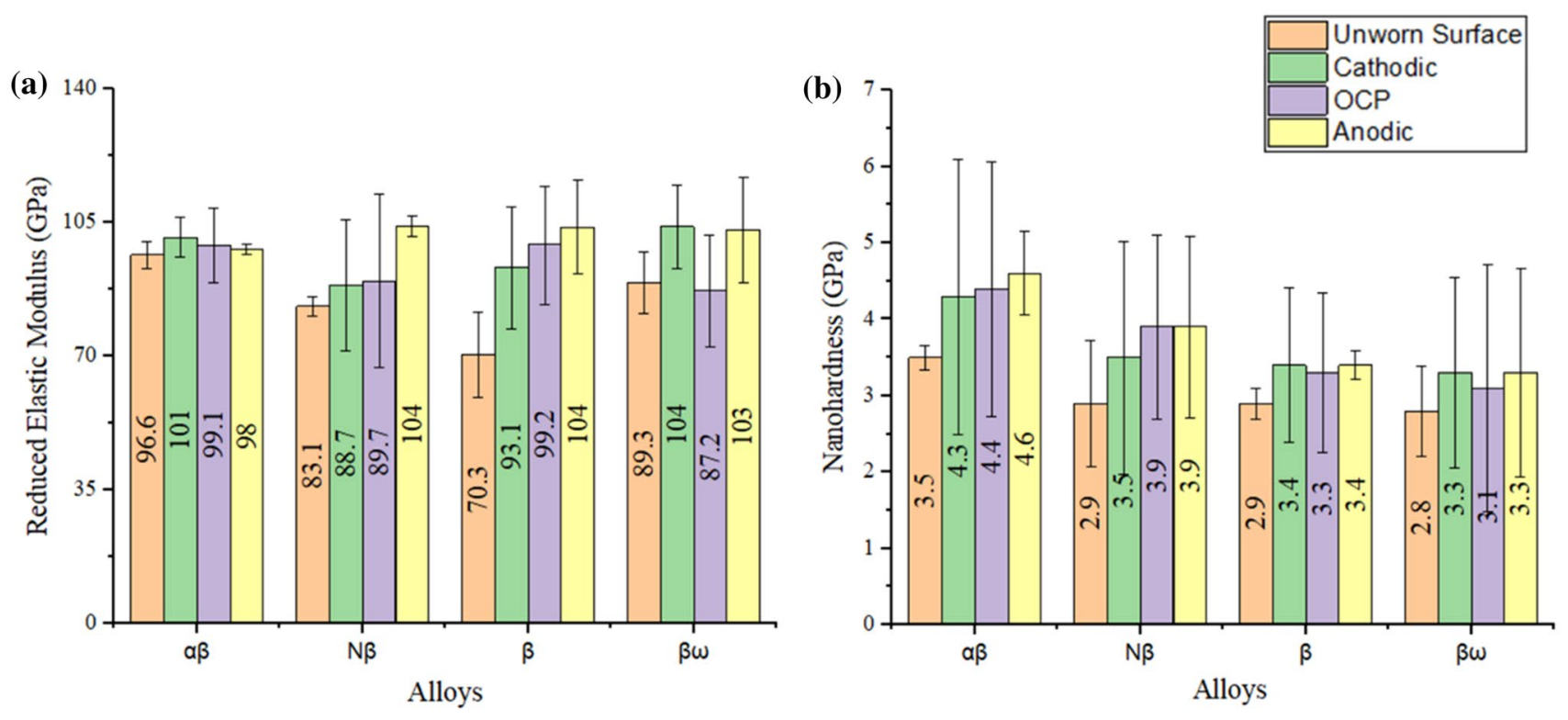

Fig. 4 Mechanical properties of the wear tracks identified by nanoindentation: a Reduced elastic moduli, b nanohardness

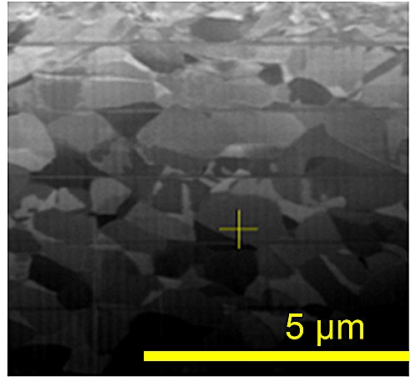

Fig. 5 The ion channelling contrast image of the wear track subsurface $-\alpha \beta$ alloy at cathodic potential and at $0.5 \mathrm{~N}$

scattered, making it challenging to differentiate statistically significant disparities.

The wear track for all tested samples had mostly similar subsurface structures after testing (Fig. 5). In general, 3 areas were identified within the deformed subsurface: a bulk, a deformed and a nanocrystalline region (Fig. 5) where fine grains were localized near the surface. Images of all worn subsurface conditions are provided in Appendix A (Fig. 9).

Subsurface alterations were observed in all condition on $\alpha \beta$ alloy, even though it was more evidenced at OCP and at cathodic condition. The same area with fine microstructure was formed on $\mathrm{N} \beta$ and $\beta$ alloys, but only at specific electrochemical potentials. Therefore, the subsurface alterations and its formation may be affected by the electrochemical condition, alloy type and microstructure. Additionally, this layer was deeper at anodic conditions on $\beta$ alloy, whereas its depth of $\alpha \beta$ alloy was smaller at this electrochemical potential. However, a similar degree of subsurface alteration occurred under all other electrochemical potentials. Finally, such a deformation layer was not identified on the $\beta \omega$ alloy in any test condition.

As expected, a fine microstructure with grains of both $\alpha$ and $\beta$ phase were confirmed on the wear track subsurface of the $\alpha \beta$ alloy by means of electron diffraction pattern analysis (Fig. 6a) at all test conditions. Evidence of subsurface alteration at both anodic and OCP conditions was observed in our TEM results, while at cathodic conditions only a slight indication of subsurface microstructural change was identified (Fig. 5).

The N $\beta$ alloy experienced major microstructural alterations on its tested subsurface (Fig. 6b) such as phase transformation evidenced by electron diffraction patterns of $\alpha, \alpha$ ", and $\omega$ phases, as well as the presence of a nanocrystalline zone. In addition, more apparent changes with precipitation of a second phase - likely $\alpha$ phase - was observed at cathodic conditions. The same observations were made at OCP, but the nanocrystalline zone was considerably thinner.

The subsurface alterations of the $\beta$ alloy at OCP (Fig. 6c) experienced phase transformation, specifically precipitations of $\alpha$ and $\omega$ phases evidenced by the TEM images, while the wear track subsurface of $\beta \omega$ alloy at the same electrochemical conditions experienced a partial transformation of $\omega$ phase to $\alpha$ phase (Fig. 6d).

The previously published part I of this study demonstrated that the tested titanium alloys had low wear track volume and material loss at anodic conditions [21]. Therefore, we opted to investigate the wear track subsurfaces of the titanium alloys at this condition to characterize their microstructural features and to detect any presence of a 
(a)

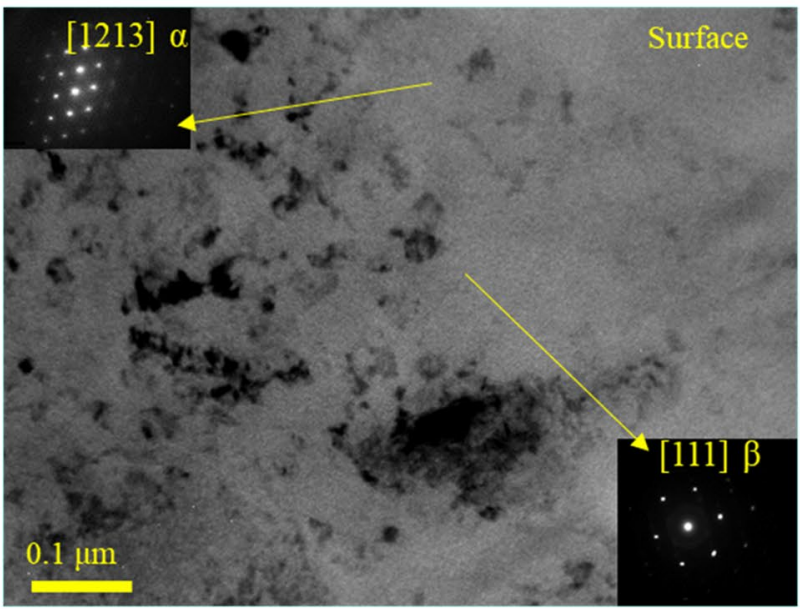

(c)

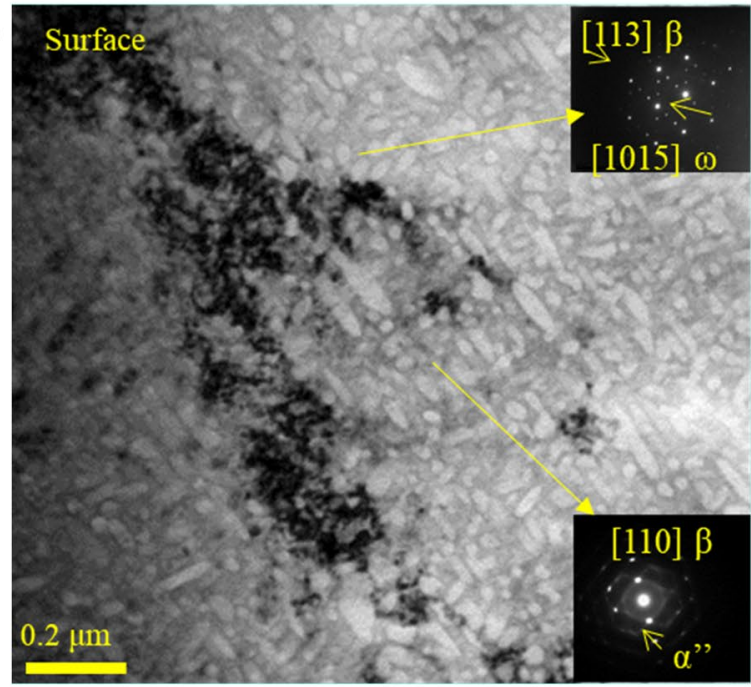

(b)

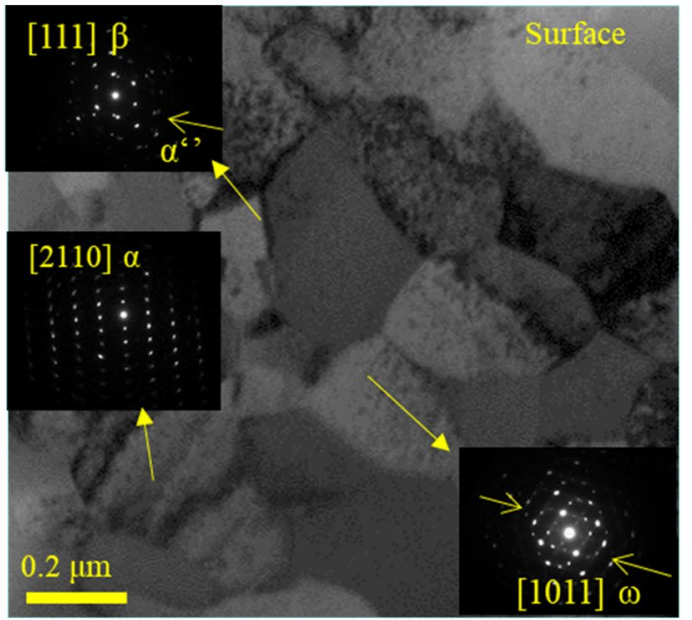

(d)

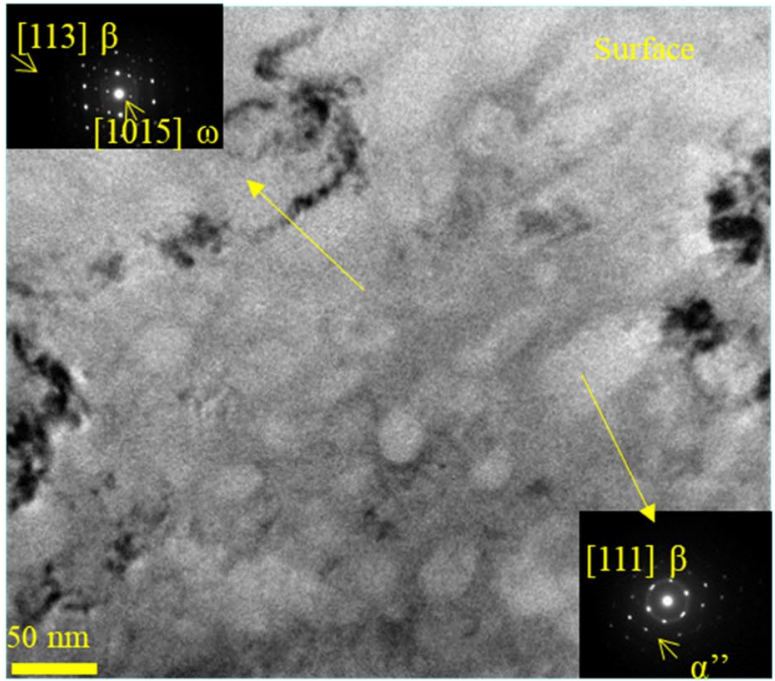

Fig. 6 Microstructural features identified by TEM imaging and diffraction patterns of the subsurface of the wear track tested at $0.5 \mathrm{~N}$ load of a $\alpha \beta$ alloy at OCP, $\mathbf{b} \mathrm{N} \beta$ alloy at anodic potential, $\mathbf{c} \beta$ alloy at OCP and $\mathbf{d} \beta \omega$ alloy at OCP

tribofilm. A nanocrystalline and strained layer of $200 \mathrm{~nm}$ was present on the subsurface of $\alpha \beta$ alloy (Fig. 7a) and rich in oxygen (Fig. 7b) with a structure mainly consisting of $\beta$ phase (Fig. 7c). On the other hand, a thicker (300 nm) and uniform nanocrystalline zone mainly of $\beta$ phase was observed on the $\mathrm{N} \beta$ alloy subsurface. Additionally, evidence of an inconsistent oxide layer was observed, which appeared to consist of compacted, oxidized wear debris.

The nanocrystalline zone identified on the $\beta$ alloy subsurface, with a microstructure mainly $\beta$ phase evidenced by electron diffraction, ranged from 100 to $600 \mathrm{~nm}$. This layer had wear debris was rich in oxygen, suggesting that the wear debris oxidised. Overall, the $\beta \omega$ alloy subsurface was generally unremarkable and the diffraction patterns indicated the presence of only $\beta$ phase and possibly an amorphous phase. Additionally, a layer rich in oxygen was observed similar to the previously mentioned alloys.

\section{Discussion}

This study aimed to identify the main acting wear mechanism, including tribofilm characterization as well as subsurface microstructural changes, of the four distinct titanium alloys (Ti13Nb13Zr, Ti12Mo6Zr2Fe, Ti29Nb13Ta4.6Zr aged at $300{ }^{\circ} \mathrm{C}$ and at $400{ }^{\circ} \mathrm{C}$ ) tested under various tribocorrosion conditions. We identified in our previously published Part I of this study [21] a synergism between wear and corrosion, where material loss was highly affected by mechanical wear and, to a lesser degree, corrosion. Overall, the material loss, wear track volume and wear rates showed lower values at anodic conditions. Here, we determined that although the overall wear mechanism remains the same with test condition or alloy type, a graphitic tribofilm was found and there were still distinct differences in the in situ microstructural subsurface alterations. 
(a)
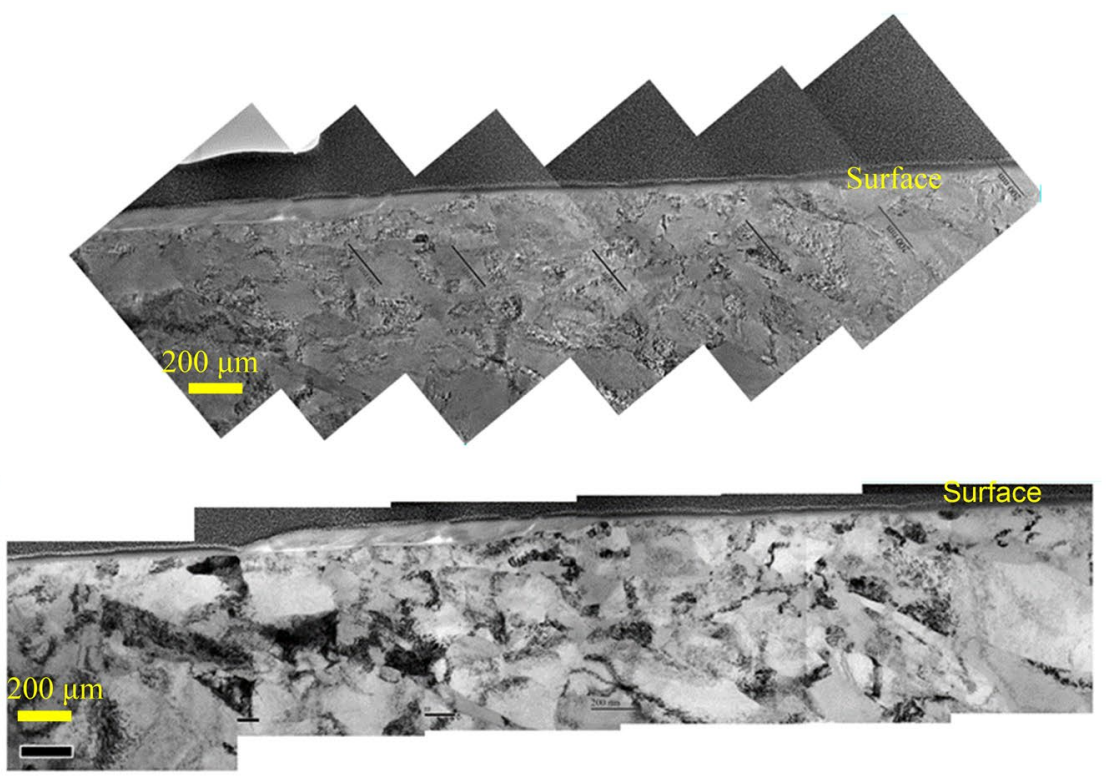

(c)

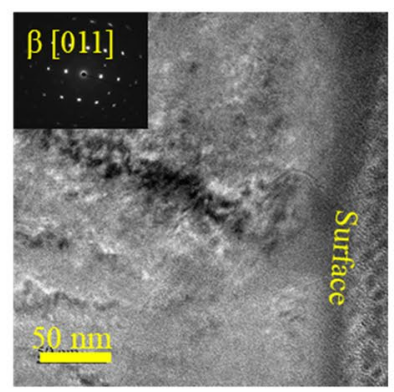

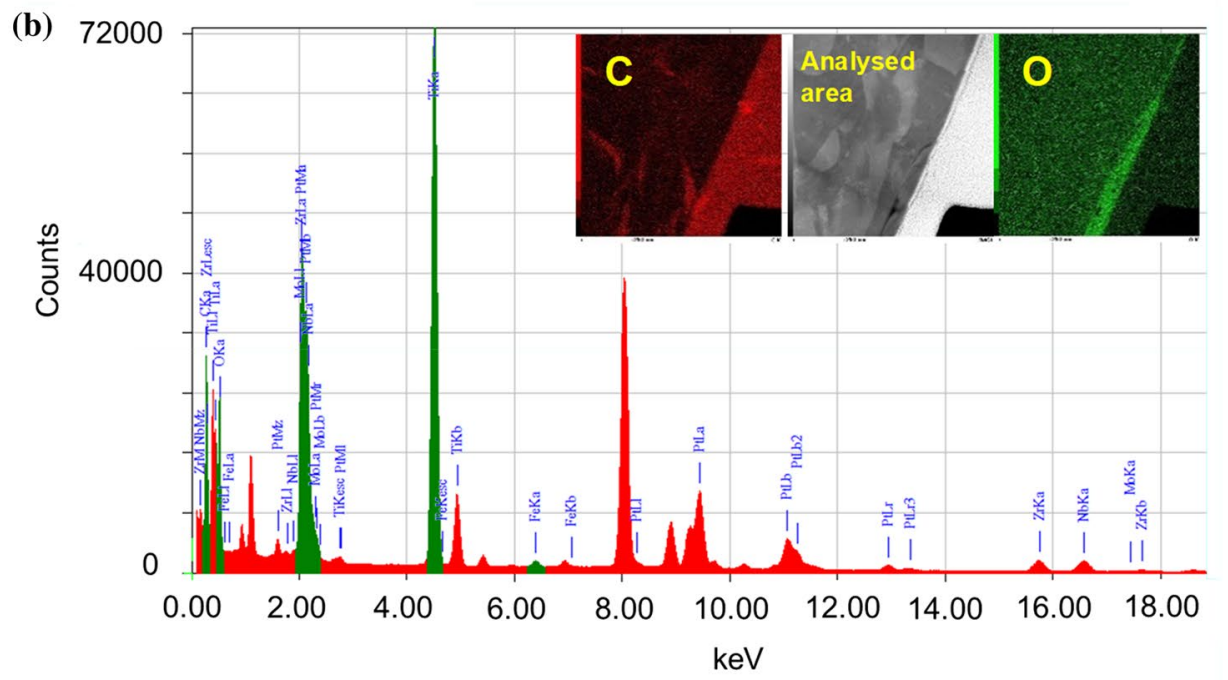

Fig. 7 a Wear track subsurface $-\mathrm{N} \beta$ alloy. b EDS spectra of the wear track subsurface- $\mathrm{N} \beta$ alloy. $\mathbf{c}$ Only $\beta$ phase was identified on the wear track subsurface at $2 \mathrm{~N}$ and at anodic potential. $\mathrm{N} \beta$ alloy is representative of all alloys in this study

\subsection{Acting Wear Mechanism and Tribofilm Characterization}

The worn surfaces predominantly exhibited wear features indicative of ploughing/micro-ploughing that is characteristic of sub-mechanism of abrasion. The locally occurring carbon-rich layer might be attributed to tribofilm formation on the surfaces in relative movement [26]. This layer is characterized by an interfacial medium originating from cyclic shear and composed of ions released from the oxide film, proteins originating from the simulated joint fluid, and wear particles (3rd bodies or tribomaterial). The tribofilm was identified in all test conditions where its presence appeared independent of alloy type and the associated microstructure, electrochemical potential or normal load (contact pressure).

The analysis of this carbonaceous tribofilm via Raman spectroscopy exhibited a characteristic double peak in most probed areas, and are indicative of $\mathrm{sp}^{2}(\mathrm{D}$ band or disordered graphite) at $1383 \mathrm{~cm}^{-1}$ and $\mathrm{sp}^{3}$ ( $\mathrm{G}$ band or single crystalline graphite) at $1567 \mathrm{~cm}^{-1}$. Both peaks represent graphitic carbon [27]. Therefore, the graphic carbon layer or tribofilm was present, independent of test condition and alloy type. Such a tribofilm was first reported by Liao et al. [28] in a hip replacement made from CoCrMo alloy (metal-on-metal). 
This study showed that the tribofilm has lubricating properties that reduces friction and is formed of albumin. Additionally, Liao et al. [29] and Yan et al. [30] suggested that the tribofilm is composed of ions and proteins. Interestingly, the present study observed a similar tribofilm which mostly consists of graphitic material and other forms of denatured proteins. According to Wimmer et al. [31, 32] CoCrMo alloys form a tribofilm only at higher loads and Mo release is vital for its formation. Therefore, the absence of Mo could potentially justify a non-continuous tribofilm on titanium alloys. By contrasting the results with those in our previously published Part I [21], it is noteworthy that tribofilm formation may have no impact on material loss. One potential reason for this may be the acting wear mechanism of abrasion. Under this mechanically dominated wear process, the tribofilm appears inconsequential. Even on the more wear-resistant CoCrMo alloy, tribofilms appear to be inactive under adverse contact conditions that enable abrasion (edge loading) [33]. However, our previous results also demonstrated lower friction at anodic conditions independent of alloy type. This may be attributed to the consistent ion release during wear at anodic conditions, which may lead to tribofilm stabilization. Ions released at anodic conditions (although specifically Mo ions) were previously shown to trigger tribofilm deposition due to redox reactions with proteins [34]. Therefore, this may explain, by a similar effect, the lower friction at anodic conditions. On the other hand, ion release was suppressed at cathodic conditions (highest friction), thereby preventing tribofilm formation [21].

\subsection{Mechanical Properties}

The differences in mechanical properties between the wear track and unworn surfaces were found to be due to the in situ subsurface alterations caused by wear and plastic deformation accumulation [35]. However, meaningful differences between nanohardness could not be distinguished due to the extensive scatter in the results. Purcek et al. [36] observed that while $\mathrm{Cp}$-Ti with fine microstructure led to an improvement on mechanical behaviour, this was inconsequential to wear properties. However, another study observed that a fine microstructure enhances the tribological behaviour of $\mathrm{Cp}-\mathrm{Ti}$ [37]. The hexagonal phase is less ductile than the bcc phase, and therefore, the deformation intensity at asperity junctions is lower [38]. However, the main acting wear mechanism was always the same, regardless of test condition and alloy type. Considering our previously published observation that material loss depends only on the applied normal load [21], it appears that the in situ surface hardening had minimal effect.

\subsection{Subsurface Characterization}

The analysis of the subsurface of the wear tracks demonstrated that in situ grain refinement occurred at the contact zones, and were found to be highly affected by the test conditions applied. The repetitive loading during sliding at the contact area was a potential reason for the observed grain refinement [39], where the oxide film may have abraded, leading to ion release and the development of a strain accumulation region. The subsurface deformation area was also observed in other alloys. Zavieh et al. [40] observed that a subsurface alteration occurred on austenitic stainless steel in $\mathrm{NaCl}$ at different electrochemical potentials. This was attributed to the shear strain accumulation at the contact, which led to a fine microstructure regardless of the electrochemical condition [40]. This observation has been reported in other studies [41], but differs from the observations found in this presented study. The tribofilm presence may explain this phenomena, as it may act as a barrier that enhances dislocation accumulation and grain refinement [42], which in theory may potentially affect the mechanical behaviour. However, as mentioned earlier, the scatter of the nanoindentation data made it challenging to distinguish statistically significant disparities.

Contact pressure was found to be varied across the wear track-potentially due to a more stable tribofilm formed at anodic potentials - which affected subsurface alterations formation. This subsequently affected the subsurface alterations leading to variations under repetitive loading, due to the variability of compression and tensile stress at the contact with the types of tribofilm [35].

In our previously published Part I [21] we indicated that this tribosystem experienced lower friction at anodic potential, explained by a more stable tribofilm formed at this electrochemical condition, as described above. Therefore, lower friction may potentially result in less strain accumulation below the contact zone, consequently leading to a lower degree of grain refinement or phase transformation. However, this hypothesis may only be applied for the alloys that experienced low subsurface modification at anodic potential, which is the case for the $\alpha \beta$ alloy, but not necessarily for both $\beta$ alloy and $\beta \omega$ alloys where the chemical composition may have a role inhibiting subsurface modifications and grain refinement. Nevertheless, further research must be conducted to elucidate this mechanism.

A not homogenously distributed tribofilm and a fine microstructure of $\beta$ phase near the subsurface were identified on the wear track subsurfaces tested at $2 \mathrm{~N}$ at anodic potential. While only grain refinement occurred on $\alpha \beta$ alloy on this area, the other 3 titanium alloys experienced $\alpha$ " and $\omega$ transformations, although these were limited and simultaneous [43]. The martensitic $\alpha$ " phase formation may have been influenced by the Ta content [44] which may explain 
Fig. 8 Diagram that summarizes the overall findings of this study

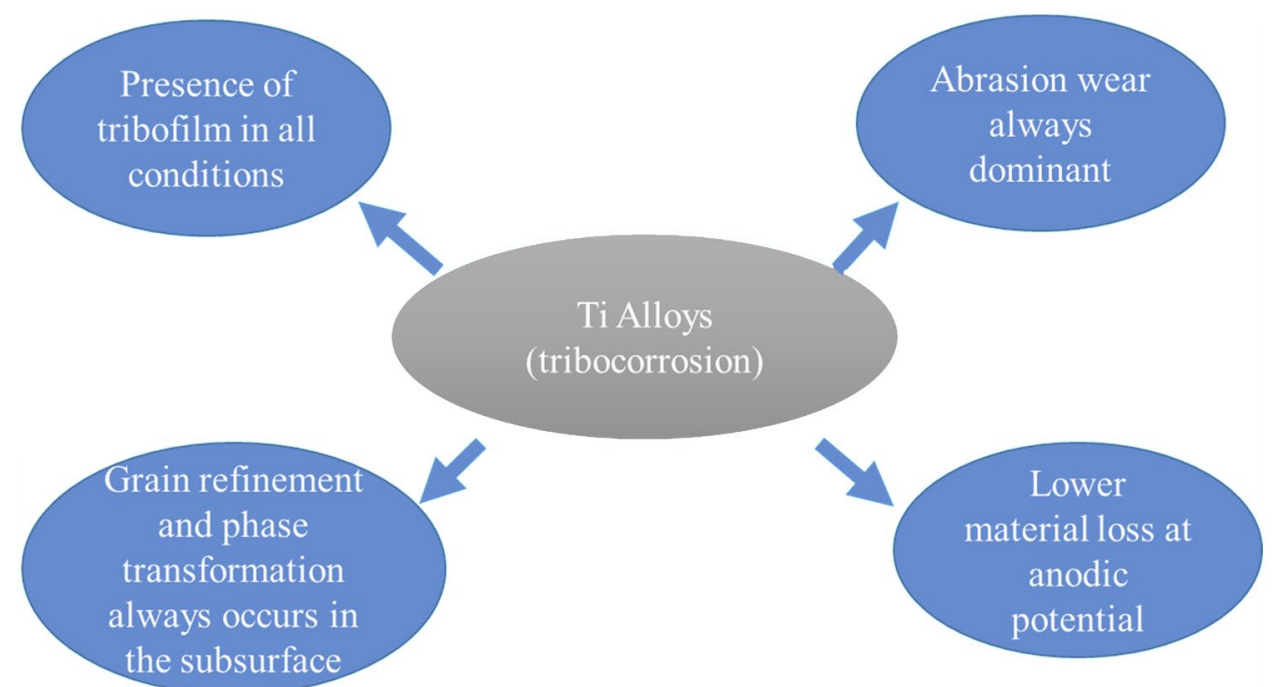

the occurrence of this transformation. Therefore, the tribocorrosion system may have induced the formation of $\omega$ phase on the alloys in this study.

The $\omega$ phase formation is detailed elsewhere $[45,46]$ and is formed from (111) bcc planes due to lattice deformation or from precipitation led by the heat transfer that occurs during friction. The $\omega$ formation is dictated by the content of $\beta$ stabilizers and has high elastic modulus in comparison to the other phases in titanium alloys [47-49]. The weak diffraction pattern reflections potentially indicate low content of $\omega$ phase in the 4 tested titanium alloys. The $\omega$ phase was also identified on worn surfaces of titanium alloys, which has also been reported by Correa et al. [50], where this phase transformation was identified on test at OCP on Ti-15Zr-7.5Mo.

It is worth noting that alloy composition affects alloy passivation, which in turn may potentially influence the tribocorrosion properties and subsurface transformation. However, this variable was not considered in this study and must be further investigated.

This study had several limitations. While the applied sliding wear tribosystem provides a baseline to understand the applicability of these alloys as biomaterials, Ti-alloy surfaces mainly experience fretting corrosion in vivo [47]. Therefore, fretting experiments to be conducted under similar conditions are of interest in future work. In addition, although our goal in this presented study was to report the changes of the mechanical properties within the wear track, the nanohardness measurements exhibited a high variability that may have resulted from the uneven surface of wear track. Such a limitation likely affected our nanoindentation tests, making it challenging to perform these tests in ideal conditions. Finally, the applied simulated joint fluid does not entirely represent the variable and complex composition of pseudo-synovial fluid. Yet, the same or similar compositions have been implemented by other studies to approximate the protein influence in a tribocorrosion system [51]. Finally, we acknowledge that other constituents, such as hyaluronic acid, would be worthwhile to be included in future studies [52-54].

\section{Conclusion}

The focus of this study was on the characterization of the worn surface and subsurface of 4 Ti-alloys with distinct chemical compositions and microstructures that underwent tribocorrosion tests at $37^{\circ} \mathrm{C}$ in simulated joint fluid consisting of newborn calf serum at varying electrochemical potentials and contact pressures. The outcomes are illustrated in Fig. 8 and summarized below:

- Abrasion wear was always dominant and independent of alloy type, electrochemical condition, and normal load (contact pressure). These variables also do not have any influence on the tribofilm structure.

- Tribofilms were present in all conditions and appeared to be formed from graphitic material and denatured protein. A mostly discontinuous film was formed, especially at anodic conditions, as evidenced by lower observed friction.

- The wear tracks at the surface had higher values of mechanical properties than that of the unworn surface. However the high level of variability in the results made it challenging to distinguish statistical differences between electrochemical conditions, alloy type and contact pressure.

- Varied intensities of grain refinement occurred below the worn surfaces of all alloy types in all test conditions. This was potentially caused by strain accumulation in the contact area. 
- Phase transformation $-\alpha$ ' and $\alpha$ ' martensite and $\omega-$ occurred on the subsurface of $\mathrm{N} \beta, \beta$ and $\beta \omega$ alloy microstructures. This observation was found to be independent of test conditions, potentially due to the volume of $\beta$ stabilizers on chemical composition.

\section{Appendix A}

See Fig. 9 (a)

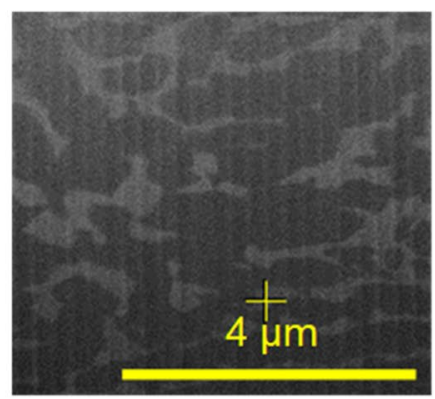

(d)

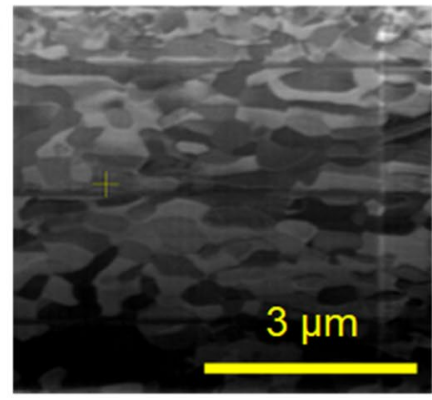

(g)

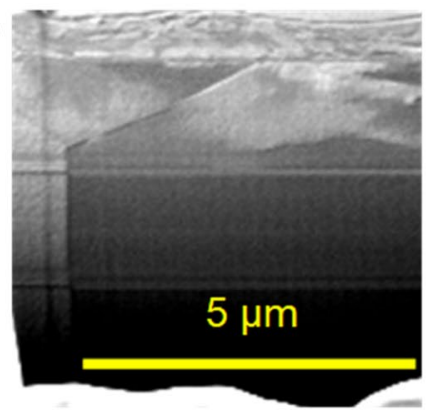

(j)

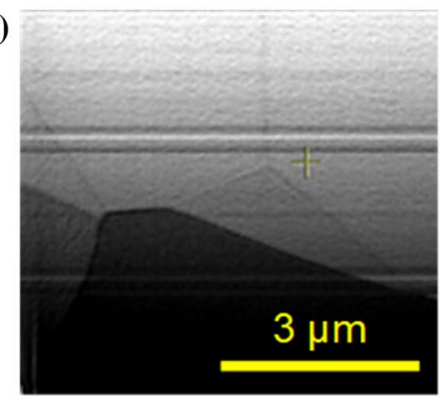

(b)

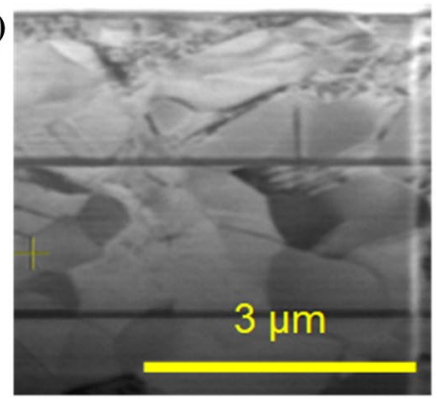

(e)

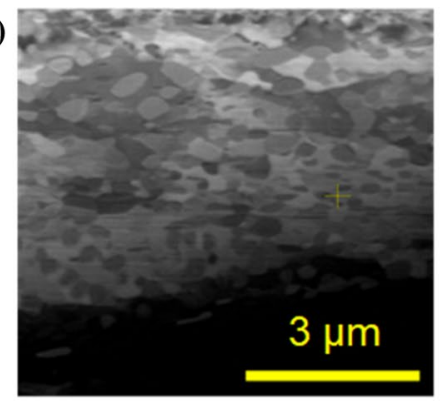

(h)

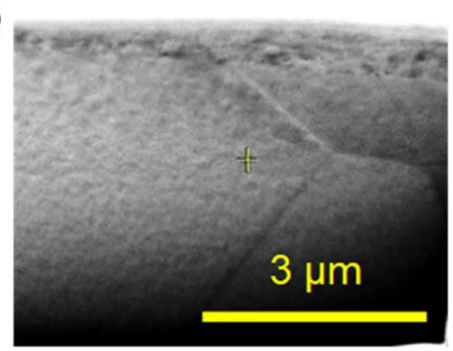

(k)

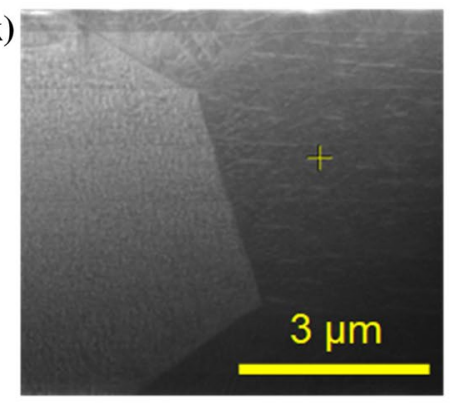

(c)

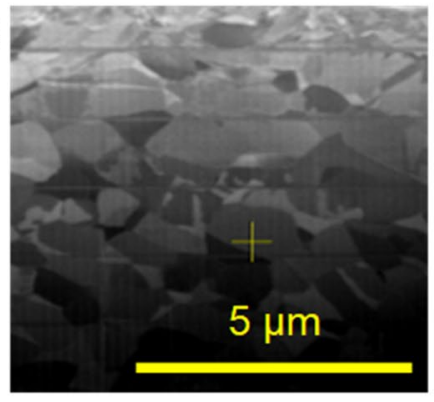

(f)

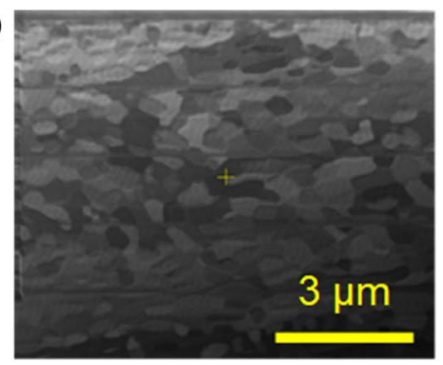

(i)

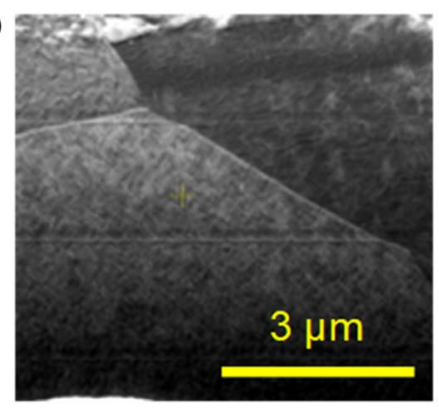

(l)

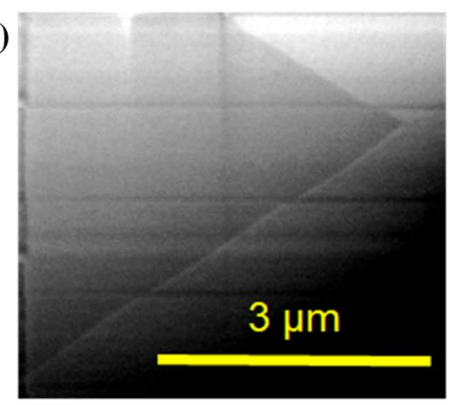

Fig. 9 The ion channelling contrast images of the wear track subsurface at $0.5 \mathrm{~N}$ of: $\alpha \beta$ alloy (a) at anodic condition, (b) at OCP and, (c) at cathodic condition. N $\beta$ alloy (d) at anodic condition, (e) at OCP, and (f) at cathodic condition. $\beta$ alloy (g) at anodic condition, (h) at OCP and, (i) at cathodic condition. $\beta \omega$ alloy (j) at anodic condition, (k) at OCP, and (l) at cathodic condition 
Funding This work was supported by Conselho Nacional de Desenvolvimento Científico e Tecnológico - CNPq.

\section{Declarations}

Conflict of interest On behalf of all authors, the corresponding author states that there is no conflict of interest.

Open Access This article is licensed under a Creative Commons Attribution 4.0 International License, which permits use, sharing, adaptation, distribution and reproduction in any medium or format, as long as you give appropriate credit to the original author(s) and the source, provide a link to the Creative Commons licence, and indicate if changes were made. The images or other third party material in this article are included in the article's Creative Commons licence, unless indicated otherwise in a credit line to the material. If material is not included in the article's Creative Commons licence and your intended use is not permitted by statutory regulation or exceeds the permitted use, you will need to obtain permission directly from the copyright holder. To view a copy of this licence, visit http://creativecommons.org/licenses/by/4.0/.

\section{References}

1. Neto, M.Q., C. Yuh, R. van Arkel, D.J. Hall, A.A.E. Orías, and R. Pourzal (2021) The effect of additive manufacturing parameters on microstructure and mechanical properties of biomedical grade Ti-6Al-4V alloy. ASTM Selected Technical Papers.

2. Kobayashi E, Wang TJ, Doi H, Yoneyama T, Hamanaka H (1998) Mechanical properties and corrosion resistance of Ti-6Al-7Nb alloy dental castings. J Mater Sci Mater Med 9(10):567-574

3. Zhou YL, Niinomi M, Akahori T, Fukui H, Toda H (2005) Corrosion resistance and biocompatibility of Ti-Ta alloys for biomedical applications. Mater Sci Eng, A 398(1-2):28-36

4. Silva JI, Alves AC, Pinto AM, Toptan F (2017) Corrosion and tribocorrosion behavior of Ti-TiB-TiNx in-situ hybrid composite synthesized by reactive hot pressing. J Mech Behav Biomed Mater 74:195-203

5. Gilbert JL, Mali S, Urban RM, Silverton CD, Jacobs JJ (2012) In vivo oxide-induced stress corrosion cracking of Ti-6Al-4V in a neck-stem modular taper: Emergent behavior in a new mechanism of in vivo corrosion. J Biomed Mater Res B Appl Biomater 100(2):584-594

6. Rodrigues DC, Urban RM, Jacobs JJ, Gilbert JL (2009) In vivo severe corrosion and hydrogen embrittlement of retrieved modular body titanium alloy hip-implants. J Biomed Mater Res Part B: Appl Biomater 88(1):206-219

7. Hall, D., R. Pourzal, C. Della Valle, J. Galante, J. Jacobs, and R. Urban, Corrosion of modular junctions in femoral and acetabular components for hip arthroplasty and its local and systemic effects, in Modularity and tapers in Total joint replacement devices. 2015, ASTM International.

8. Hemmilä M, Karvonen M, Keemu H, Seppänen M, Mäkelä K (2020) Accolade TMZF trunnion corrosion and mechanical failure $9 \mathrm{yr}$ after primary surgery: A case report and treatment options. Current Orthopaedic Practice 31(3):318-321

9. Bansal, T., S. Aggarwal, M.S. Dhillon, and S. Patel (2020) Gross trunnion failure in metal on polyethylene total hip arthroplasty-a systematic review of literature. International Orthopaedics. p. 1-13.

10. Banerjee S, Cherian JJ, Bono JV, Kurtz SM, Geesink R, Meneghini RM, Delanois RE, Mont MA (2015) Gross trunnion failure after primary total hip arthroplasty. J Arthroplasty 30(4):641-648
11. Espallargas N, Fischer A, Munoz AI, Mischler S, Wimmer MA (2017) In-situ Generated Tribomaterial in Metal/Metal Contacts: current understanding and future implications for implants. Biotribology (Oxf) 10:42-50

12. Lütjering $G$ (1998) Influence of processing on microstructure and mechanical properties of $(\alpha+\beta)$ titanium alloys. Mater Sci Eng, A 243(1-2):32-45

13. Shivaram MJ, Arya SB, Nayak J, Panigrahi BB (2021) Tribocorrosion behaviour of biomedical porous $\mathrm{Ti}-20 \mathrm{Nb}-5 \mathrm{Ag}$ alloy in simulated body fluid. Journal of Bio-and Tribo-Corrosion 7(2):1-9

14. Liu Y, Zhu D, Gilbert JL (2021) Sub-nano to nanometer wear and tribocorrosion of titanium oxide-metal surfaces by in situ atomic force microscopy. Acta Biomater 126:477-484

15. Guan J, Jiang X, Xiang Q, Yang F, Liu J (2021) Corrosion and tribocorrosion behavior of titanium surfaces designed by electromagnetic induction nitriding for biomedical applications. Surf Coat Technol 409:126844

16. Caha I, Alves A, Chirico C, Pinto A, Tsipas S, Gordo E, Toptan $\mathrm{F}$ (2020) Corrosion and tribocorrosion behavior of Ti-40Nb and Ti-25Nb-5Fe alloys processed by powder metallurgy. Metall and Mater Trans A 51(6):3256-3267

17. Tang X, Ahmed T, Rack HJ (2000) Phase transformations in Ti-Nb-Ta and Ti-Nb-Ta-Zr alloys. J Mater Sci 35(7):1805-1811

18. Afonso CRM, Aleixo GT, Ramirez AJ, Caram R (2007) Influence of cooling rate on microstructure of $\mathrm{Ti}-\mathrm{Nb}$ alloy for orthopedic implants. Mater Sci Eng, C 27(4):908-913

19. Afonso CR, Ferrandini PL, Ramirez AJ, Caram R (2010) High resolution transmission electron microscopy study of the hardening mechanism through phase separation in a beta-Ti$35 \mathrm{Nb}-7 \mathrm{Zr}-5 \mathrm{Ta}$ alloy for implant applications. Acta Biomater 6(4):1625-1629

20. Ferrandini PL, Cardoso FF, Souza SA, Afonso CR, Caram R (2007) Aging response of the Ti-35Nb-7Zr-5Ta and Ti-35Nb7Ta alloys. J Alloy Compd 433(1-2):207-210

21. Neto MQ, Rainforth WM (2020) Effect of Potential and Microstructure on the Tribocorrosion Behaviour of Beta and Near Beta Ti Alloys I. Biotribology 24:100141

22. Caha I, Alves AC, Kuroda PAB, Grandini CR, Pinto AMP, Rocha LA, Toptan F (2020) Degradation behavior of Ti-Nb alloys: Corrosion behavior through 21 days of immersion and tribocorrosion behavior against alumina. Corros Sci 167:108488

23. Hee AC, Martin PJ, Bendavid A, Jamali SS, Zhao Y (2018) Tribocorrosion performance of filtered-arc-deposited tantalum coatings on Ti-13Nb-13Zr alloy for bio-implants applications. Wear 400:31-42

24. Galliano F, Galvanetto E, Mischler S, Landolt D (2001) Tribocorrosion behavior of plasma nitrided Ti-6Al-4V alloy in neutral $\mathrm{NaCl}$ solution. Surf Coat Technol 145(1-3):121-131

25. Neto, M., (2019) Understanding the wear and tribocorrosion processes and mechanisms of titanium alloys in bovine serum solution.

26. Hesketh J, Ward M, Dowson D, Neville A (2014) The composition of tribofilms produced on metal-on-metal hip bearings. Biomaterials 35(7):2113-2119

27. Dillon RO, Woollam JA, Katkanant V (1984) Use of Raman scattering to investigate disorder and crystallite formation in as-deposited and annealed carbon films. Phys Rev B 29(6):3482

28. Liao Y, Pourzal R, Wimmer MA, Jacobs JJ, Fischer A, Marks LD (2011) Graphitic tribological layers in metal-on-metal hip replacements. Science 334(6063): 1687-1690

29. Liao Y, Hoffman E, Wimmer M, Fischer A, Jacobs J, Marks L (2013) CoCrMo metal-on-metal hip replacements. Phys Chem Chem Phys 15(3):746-756 
30. Yan Y, Neville A, Dowson D (2007) Biotribocorrosion of CoCrMo orthopaedic implant materials - assessing the formation and effect of the biofilm. Tribol Int 40(10-12):1492-1499

31. Wimmer MA, Laurent MP, Mathew MT, Nagelli C, Liao Y, Marks LD, Jacobs JJ, Fischer A (2015) The effect of contact load on CoCrMo wear and the formation and retention of tribofilms. Wear 332:643-649

32. Wimmer MA, Fischer A, Büscher R, Pourzal R, Sprecher C, Hauert R, Jacobs JJ (2010) Wear mechanisms in metal-on-metal bearings: The importance of tribochemical reaction layers. J Orthop Res 28(4):436-443

33. Pourzal R, Catelas I, Theissmann R, Kaddick C, Fischer A (2011) Characterization of wear particles generated from CoCrMo alloy under sliding wear conditions. Wear 271(9-10):1658-1666

34. Martin EJ, Pourzal R, Mathew MT, Shull KR (2013) Dominant role of molybdenum in the electrochemical deposition of biological macromolecules on metallic surfaces. Langmuir 29(15):4813-4822

35. Straffelini G (2015) Friction and wear: methodologies for design and control. Springer, NY

36. Purcek G, Saray O, Kul O, Karaman I, Yapici GG, Haouaoui M, Maier HJ (2009) Mechanical and wear properties of ultrafinegrained pure Ti produced by multi-pass equal-channel angular extrusion. Mater Sci Eng, A 517(1-2):97-104

37. Humphreys FJ, Hatherly M (2012) Recrystallization and related annealing phenomena. Elsevier, Amsterdam

38. Hutchings, I. and P. Shipway, Tribology: friction and wear of engineering materials. 2017: Butterworth-Heinemann.

39. Landolt D, Mischler S (2011) Tribocorrosion of passive metals and coatings. Elsevier, Amsterdam

40. Zavieh AH, Espallargas N (2016) The role of surface chemistry and fatigue on tribocorrosion of austenitic stainless steel. Tribol Int 103:368-378

41. Perret J, Boehm-Courjault E, Cantoni M, Mischler S, Beaudouin A, Chitty W, Vernot JP (2010) EBSD, SEM and FIB characterisation of subsurface deformation during tribocorrosion of stainless steel in sulphuric acid. Wear 269(5-6):383-393

42. Munoz AI, Espallargas N (2011) Tribocorrosion mechanisms in sliding contacts. Tribocorrosion of Passive Metals and Coatings. Elsevier, pp 118-152

43. Zhao X, Niinomi M, Nakai M, Hieda J (2012) Effect of deformation-induced $\omega$ phase on the mechanical properties of metastable $\beta$-type Ti-V alloys. Mater Trans 53(8):1379-1384

\section{Authors and Affiliations}

\section{Mozart Queiroz Neto ${ }^{1}\left[\right.$. William Mark Rainforth ${ }^{1}$}

Mozart Queiroz Neto

mozart_q_neto@rush.edu
44. Leyens C, Peters M (2003) Titanium and titanium alloys: fundamentals and applications. Wiley, NY

45. Ping D (2014) Review on $\omega$ phase in body-centered cubic metals and alloys. Acta Metallurgica Sinica (English Letters) 27(1):1-11

46. Zheng, Y., R.E. Williams, D. Choudhuri, T. Alam, R. Banerjee, D. Banerjee, and H.L. Fraser. On the mechanism of nucleation and growth of omega phase in beta titanium alloys'.

47. Geetha M, Singh AK, Asokamani R, Gogia AK (2009) Ti based biomaterials, the ultimate choice for orthopaedic implants-a review. Prog Mater Sci 54(3):397-425

48. Li Y, Yang C, Zhao H, Qu S, Li X (2014) New developments of Ti-based alloys for biomedical applications. Materials (Basel) 7(3):1709-1800

49. Shao G, Tsakiropoulos $\mathrm{P}$ (2000) On the $\omega$ phase formation in $\mathrm{Cr}-\mathrm{Al}$ and $\mathrm{Ti}-\mathrm{Al}-\mathrm{Cr}$ alloys. Acta Mater 48(14):3671-3685

50. Correa DRN, Kuroda PAB, Grandini CR, Rocha LA, Oliveira FGM, Alves AC, Toptan F (2016) Tribocorrosion behavior of $\beta$-type Ti-15Zr-based alloys. Mater Lett 179:118-121

51. Namus, R. and W.M. Rainforth, Influence of protein adsorption on tribocorrosion behaviour of CoCrMo biomedical-grade alloys. Tribology International, 2020: p. 106364.

52. More NS, Diomidis N, Paul SN, Roy M, Mischler S (2011) Tribocorrosion behavior of $\beta$ titanium alloys in physiological solutions containing synovial components. Mater Sci Eng, C 31(2):400-408

53. Costa BC, Tokuhara CK, Rocha LA, Oliveira RC, Lisboa-Filho PN, Pessoa JC (2019) Vanadium ionic species from degradation of Ti-6Al-4V metallic implants: In vitro cytotoxicity and speciation evaluation. Mater Sci Eng, C 96:730-739

54. Radice S, Liu S, Pourzal R, Laurent MP, Wimmer MA (2019) Effects of bovine serum albumin and hyaluronic acid on the electrochemical response of a CoCrMo alloy to cathodic and anodic excursions. Journal of bio-and tribo-corrosion 5(4):1-12

55. Anaee, R.A.M. and M.H. Abdulmajeed, Tribocorrosion. Advances in Tribology, 2016.

Publisher's Note Springer Nature remains neutral with regard to jurisdictional claims in published maps and institutional affiliations.

1 Department of Materials Science and Engineering, University of Sheffield, Sir Robert Hadfield Building, Mappin Street, Sheffield S1 3JD, UK 